\title{
A NOVEL APPROACH TO EDUCATING ENGINEERS: LEARNING IN AN INVERTED CLASSROOM THROUGH PROBLEMS DESIGNED BY ENGINEERING PROFESSIONALS
}

\author{
Teodora Rutar Shuman* \\ Seattle University, Mechanical Engineering Department, USA \\ Gregory S. Mason \\ Seattle University, Mechanical Engineering Department, USA \\ Yean-Lin Han \\ Seattle University, Mechanical Engineering Department, USA \\ Kathleen E. Cook \\ Seattle University, Psychology Department, USA
}

This paper presents a novel approach to educating engineers by using an inverted classroom (IC) to facilitate learning through in-class solving of multi-faceted problems designed by engineering professionals. The objective of this approach is to develop an instructional framework that promotes self-directed learning and enhances problem-solving skills in undergraduate engineering students without sacrificing knowledge of fundamental engineering principles. In this framework, material traditionally covered in a lecture format is moved outside of class time, developed for an on-line format, and made available in an online learning management system. In-class time is used to solve engineering problems in teams and under guidance of an instructor. The problems are co-developed with practicing engineers from aerospace, medical device, HVAC and process industries. The framework was implemented in a Heat Transfer course. Students taught using the new framework showed improvement in self-directed learning and problem-solving skills over students taught in a traditional setting without losing basic skills.

Key words: Inverted (flipped) classroom, Problem-solving skills, Authentic problems, Multi-faceted problems

\section{INTRODUCTION}

One of the challenges of modern engineering education is that programs must address not only technical topics but also prepare graduates for real engineering practice. More often than not, engineering practice means solving open-ended and ambiguous problems in rapidly changing technical environment. Furthermore, industry is looking for graduates who require little-to-no on-the-job training. These trends present new challenges for engineering education and may require adoption of novel teaching methods.

One method for teaching problem solving is Problem Based Learning (PBL). In PBL, students are tasked with solving large open-ended problems during class-time and under supervision of instructor. Problems are crafted so that the students must address and learn technical content from the course. PBL has been shown to be an effective framework for teaching engineering fundamentals within the context of openended problems. Studies [11, 15] show improved learning when classroom instruction is problembased as well as an improved ability to solve open-ended problems [16].

PBL has three notable drawbacks. First, PBL students often perform poorer than those taught in a traditional class when tested using standardized tests on fundamental engineering principles [10]. This is especially true for self-paced and self-directed PBL activities [09]. This problem is usually overcome by creating a PBL environment that is structured, assessed, and supported [18]. Second, extra class time is necessary for solving open-ended problems, which leads to a reduction in the total number of concepts covered in a 
course [07]. Third, PBL problems are structured specifically to the course objectives and so do not always represent real-world problems.

An inverted (or flipped) classroom can free class time with minimal effect on content and so provides a promising framework for PBL instruction. In an Inverted Classroom (IC), lecture material is moved outside of the class, freeing in-class time for learner-centered activities. Course content is delivered through a variety of mediums including lecture videos, simulations, interactive problem solving and other online materials [17, 13].

The Inverted Classroom approach has been shown to be an effective delivery method in several studies [04,06]. The IC does not negatively affect student performance on traditional class and standardized tests [14]. IC can promote selfdirected learning and help develop professional problem solving skills because the format teaches the student to find and interpret the information needed to solve problems [02].

Challenges with the Inverted Classroom can be overcome by (1) requiring an online quiz before class to ensure preparedness, (2) keeping videos less than 30 minutes, (3) fixing student misconceptions by spending the first 10 minutes of class answering questions or holding mini-lectures, and (4) using multi-media for online content to engage students [17, 13].

Those results suggest that an IC and PBL could be successfully integrated to improve student self-directed learning and problem-solving skills without sacrificing a strong understanding of fundamental engineering principles. The approach described in this paper goes one step beyond IC and traditional PBL. The problems used in the classroom to facilitate learning are multifaceted and designed by practicing engineers who work for aerospace, medical device, HVAC and process industries. These problems were open-ended, truly authentic, and very different than textbook-type problems typically used in the classroom. Using problems that are co-developed with industrial partners addresses the concern that PBL may not represent real-world problems.

This paper is a continuation of a paper presented at the 2015 ASEE Annual conference in the NSF Grantee's Poster Session [05]. The new material includes implementation details and preliminary results obtained after applying industry-supplied problems in a heat transfer course that is taught using an IC framework. The project was funded by the National Science Foundation [08].

\section{PROJECT OVERVIEW}

The goal of the project is to improve self-directed learning and students' problem-solving skills while maintaining the number of engineering concepts taught in a course and student understanding of fundamental engineering principles. This is accomplished by using an IC approach with real-world problems. This instructional framework was developed, implemented, and then tested in a Heat Transfer course. The course is taught in the junior year of a Bachelor of Science in Mechanical Engineering degree program. This course was chosen because it is an upper-level course and has many applications in engineering practice. The latter was important to enable design of problems supplied by practicing engineers.

The practicing engineers supplied problem statements, documentation, experimental data, and vendor specification sheets. These problems were solved by students working in teams over several class periods. The instructor did not lecture during the class time other than to give short explanations to answer students' questions. All of the lectures were recorded and posted on a web-accessible Learning Management System (Canvas) [03]. Other course materials, such as tutorials and classic homework-style example problems were also moved outside of the classroom and posted on Canvas.

The framework is loosely based on the Bloom's Taxonomy. By inverting the classroom, knowledge and comprehension are attained through videos and other on-line resources outside of the classroom, whereas application, analysis and synthesis are attained through using authentic, open-ended engineering problems.

\section{IMPLEMENTATION}

The implementation of this framework was designed to fulfil two essential project goals:

1. Develop and implement an instructional framework using an Inverted Classroom to facilitate learning through multi-faceted problems designed by engineering professionals, and

2. Evaluate the effectiveness of this instructional framework on student performance and attitudes. 
3. To fulfil these goals the Heat Transfer course was offered in two phases: a control setting (Phase I) and a test setting using the new framework presented here (Phase II).

\section{PHASE I: ESTABLISHING A CONTROL FOR THE STUDY}

In the first year of the study, the heat transfer was taught as a traditional course, using a standard textbook [01]. This served as the control for the study and provided a reference for comparison with a course taught using the new framework. Heat Transfer is taught over a 10 -week quarter. The course is taught in three 65-minute classes per week with a 90-minute laboratory session once per week. Table 1 lists the topics covered in the course.

Table 1: Heat Transfer Topics

\begin{tabular}{|c|c|c|}
\hline Conduction & Convection & Radiation \\
\hline Conservation of energy & Newton's law of cooling & Planck's law \\
\hline Conduction rate equation & Convective heat transfer coefficient & Wein's displacement law \\
\hline \hline Heat diffusion equation & Boundary layers & Blackbody radiation \\
\hline Boundary and initial conditions & External flow & Radiation geometry \\
\hline 1-D, steady-state conduction & Internal flow & Surface properties \\
\hline Conduction with thermal generation & Natural (free) convection & Radiation exchange \\
\hline Extended surfaces: fins and pins & Heat exchangers: Basic design & \\
\hline 2-D conduction & Heat exchangers: LMTD method & \\
\hline Transient conduction & Heat exchangers: Effectiveness/NTU method & \\
\hline
\end{tabular}

Phase I was implemented in spring of 2014. As it was taught in a traditional setting, each topic was introduced by the instructor in class. Inclass time was used to lecture and solve textbook-type examples, both done by instructor, with an occasional active-learning exercise in which students solved a small problem or part of a problem. Students were expected to work on textbook-type homework problems outside of class (see Figure 1.)

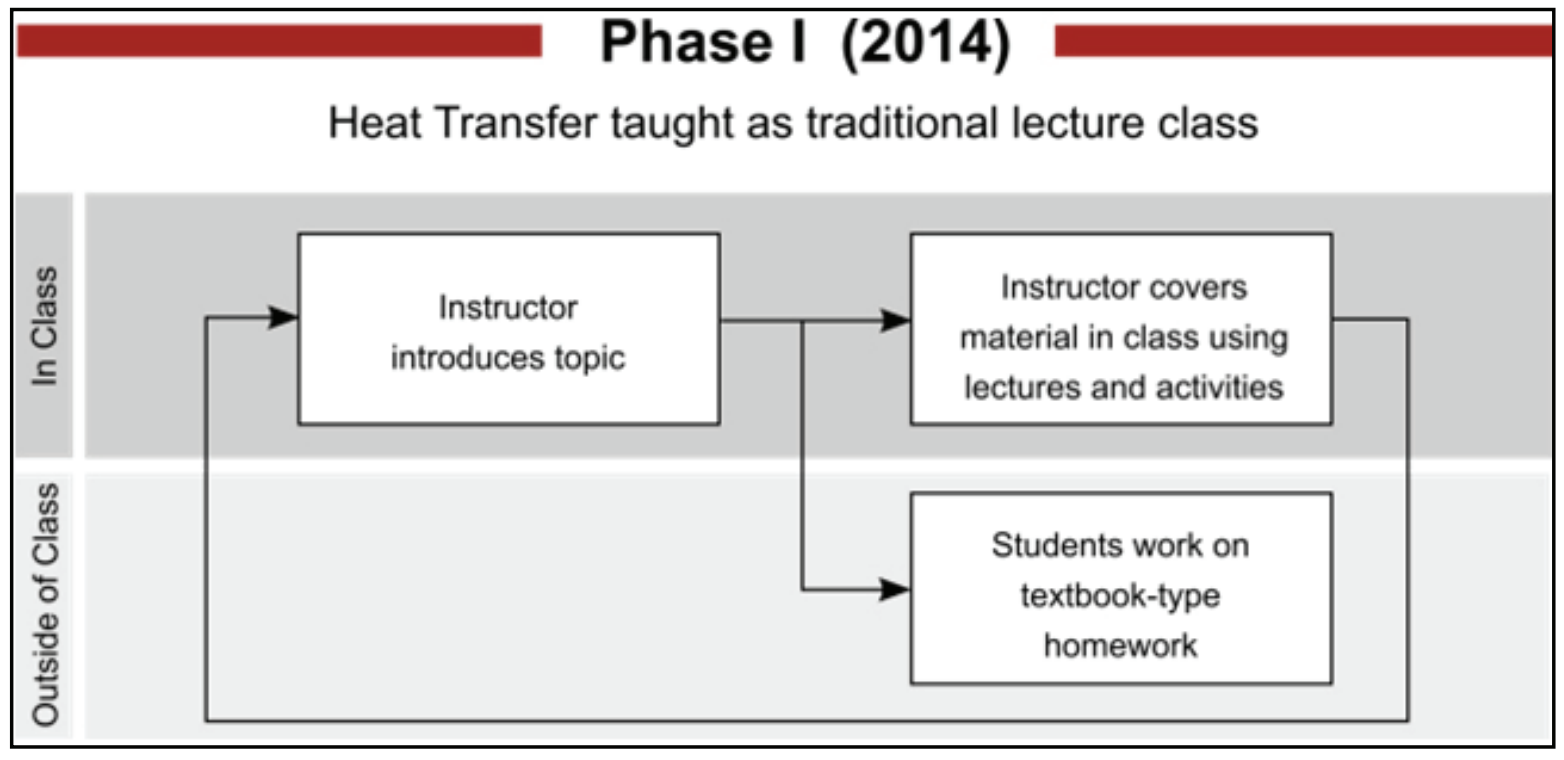

Figure 1. Phase I: traditional lecture course

During Phase I, detailed assessment data were collected on student performance. All individual exam, quiz, and homework problems were mapped to specific course topics, see Table 1. Two open-ended design problems were assigned, one early and the other late in the term.
Students were given a week to solve each. The instructor acted as the client for the problem and so did not provide any technical assistance. At the end of the project each student gave a five minute presentation to a panel of three faculty members. They were graded, using a rubric de- 
veloped specifically for this assessment.

Students in the traditional course completed the Heat and Energy Concept Inventory (HECl) test [12]. This test is designed to evaluate the following four concepts: a) temperature vs. energy, b) temperature vs. perceptions of hot and cold; c) factors that affect the rate vs. amount of heat transfer; d) thermal radiation.

Three original assessment tools were developed and applied end-of-term to: a) discern students' understanding of real-world engineering activities, b) measure students' interest in, commit- ment to, liking in, and identification with engineering programs and careers, and c) measure students' confidence and efficacy in their engineering skills.

\section{PHASE II: IC WITH REAL-WORLD PROBLEMS}

In Phase II of the project, implemented in spring 2015 , the heat transfer course was taught again by the same instructor. This time the course was taught using the new framework (see Figure 2).

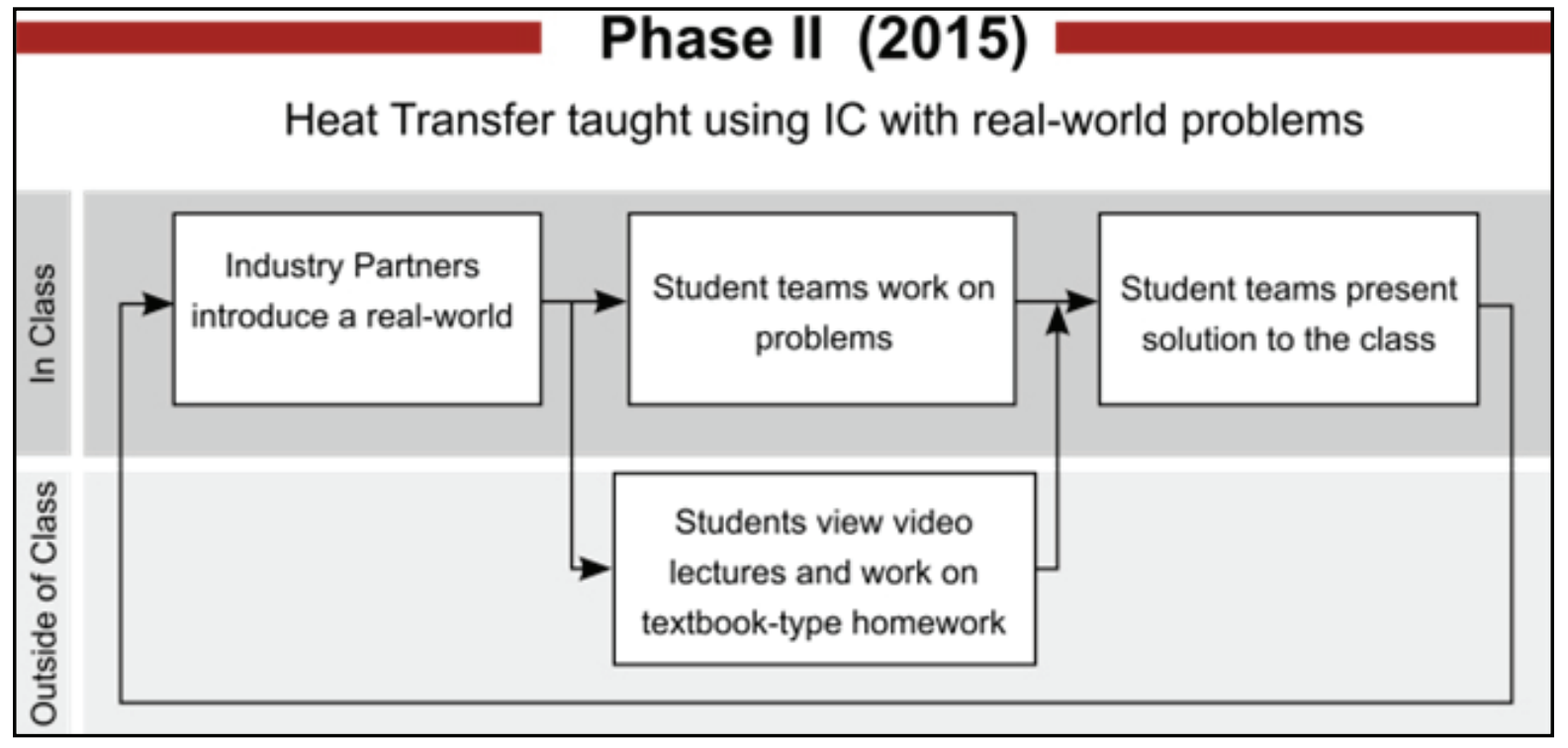

Figure 2. Phase II: IC with real-world problems

Open-ended, authentic engineering problems, designed by engineering professionals, were introduced in class to provide motivation and context for self-directed learning assignments. The engineering professional actually came to class to introduce the problems. See Table 2 for an example of an authentic engineering problem. Students were divided into three-person teams and were given 4 to 5 class periods to solve the problems. Problem-solving took most of the class periods. Other in-class activities included occasional mini-lectures, demonstrations, and questions/answer sessions facilitated by the course instructor and aimed at guiding students to: a) determine the knowledge they must gain and information they must gather to solve each problem, and b) build upon knowledge acquired from self-directed learning. Outside of class time, students learned the needed fundamental engineering principles through the IC by identifying and watching lecture videos and studying other materials on Canvas. This scaffolded ap- proach was expected to help develop students' ability to self-direct their learning. An online quiz associated with each topic encouraged students to watch the videos and study other database materials in preparation for problem-solving sessions.

Again, detailed assessment data on student performance were collected. Similar individual exam, quiz, and homework problems were given to assess engineering fundamentals.

The same two open-ended design problems were assigned in Phase II. The problems were assigned in the same time periods of the term and in the same format as in Phase I.

Other assessment tools included the $\mathrm{HECl}$ and the same original end-of-term assessment tools as those applied in the traditional setting (see above). Additional assessment tools were developed to evaluate project performance and student problem-solving skills. 
Table 2: An authentic engineering problem with learning objectives and on-line resources

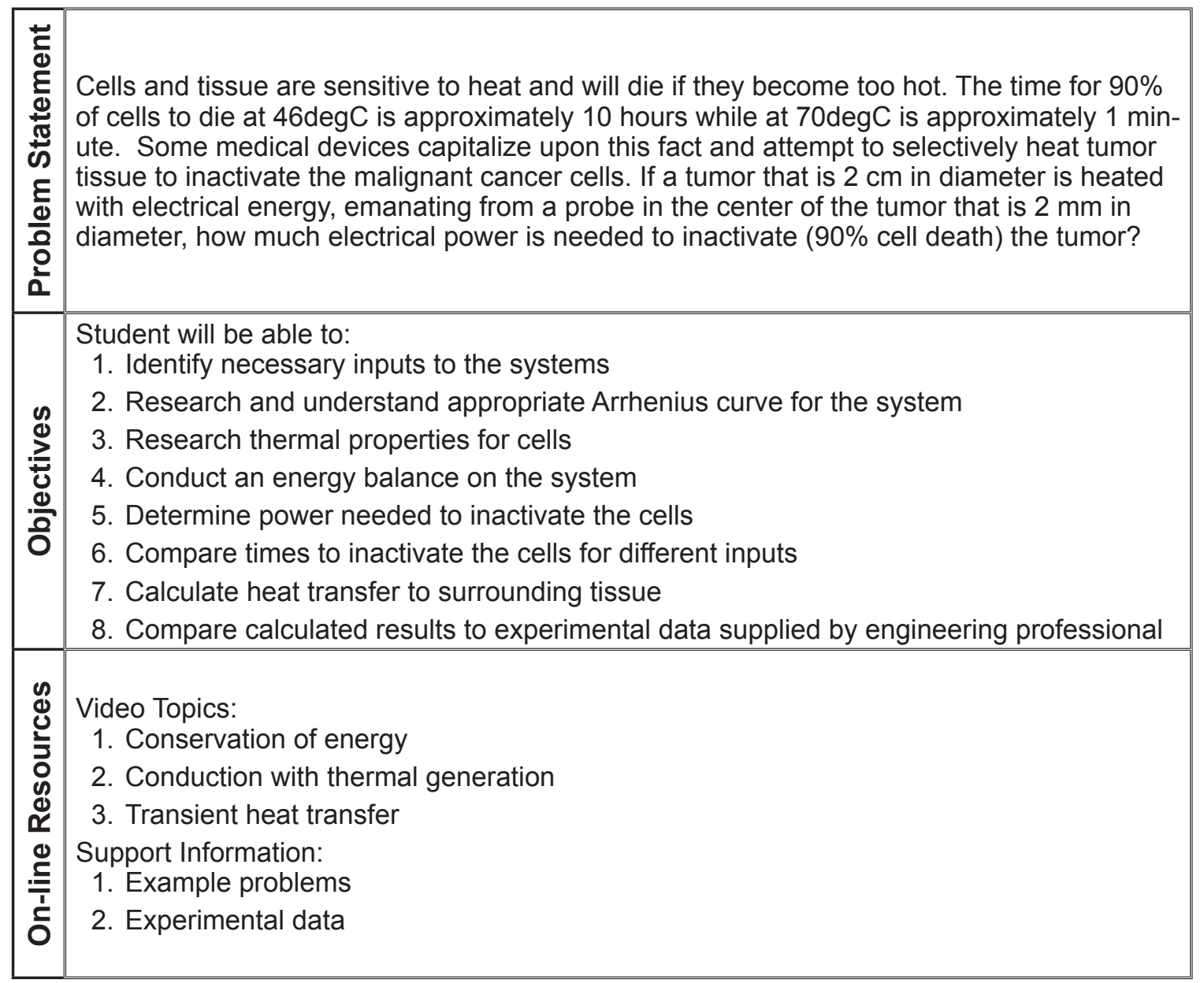

\section{RESULTS AND DISCUSSION}

A key component of this project was to develop and implement an instructional framework using an Inverted Classroom to facilitate learning through multi-faceted problems designed by engineering professional. The development involved creating a database of lectures that had to be recorded, edited, and posted on Canvas. The lectures were made by recording voice over power point presentation in a screen-capture format. It was found that lectures take a shorter time when they are delivered in electronic format then when delivered in the classroom because they don't contain pauses typically associated with giving a lecture in person; however, students can pause and replay the electronic lectures if needed. The lectures were only 8-12 minutes long.

Identifying projects supplied by engineering professionals was also an essential part of the development of this framework. The projects had to come from different industries to assure variety and elicit students' interests and understanding of engineering profession. Engineers were asked to design problems that cover a general topic in heat transfer. The topics were conservation of energy, conduction, unsteady heat transfer, heat exchangers, and radiation. The problems were not modified to assure their authenticity. The coordination with engineers did present several challenges and extra time should be planned for it. The engineers provided feedback to the students after the problem solutions were presented to them.

The implementation of this framework does require change in how students approach studying. This new approach requires more from the students than traditional lectures. They are required to watch lectures and solve textbook-type example problems; those activities are covered during class in traditional setting. As a result, the new framework needs to be administered carefully. It's easy under this format to overwhelm students with work.

On the positive side, the on-line lectures remain a resource students can access any time to understand technical content better. And, authen- 
tic problem-solving is an additional skill. Instructor and other professors involved in this project have observed deeper learning and increased ability to solve open-ended problems with students taught using the new framework. Those students had higher scores on exams than those in the traditional course. They also performed better on open-ended design problems. That is, they presented solutions that were more realistic. Furthermore, the instructor was able to cover the same amount of content in the course using the new framework as in the traditional course offering.

The novel approach to educating engineers presented in this paper is considered successful and is recommended to other educators because students demonstrated increased problem-solving performance both on open-ended design problems and on traditional exams without sacrificing the course technical content.

\section{CONCLUSIONS}

The goal of this project was to develop an instructional framework that addresses students' ability to solve open-ended design problems and their knowledge of fundamental heat transfer topics. The framework uses an IC format to disseminate fundamental course concepts, freeing class time for problem solving activities. The project studies this new framework in the context of a Heat Transfer course. A traditional, lecturestyle course offering was used as control for this study. The new framework presents many challenges during development and implementation. However, the results indicate that students in the course using this new framework learn deeper and can solve open-ended problems better than those in traditional settings.

\section{REFERENCES}

1) Bergman, T. L., Lavine, A.S., Incropera, F.P., \& DeWitt, D.P. (2011) Fundamentals of Heat and Mass Transfer, 7th Ed., Wiley, Hoboken, NJ.

2) Bland, L., (2006) Apply Flip/Inverted Classroom Model in Electrical Engineering to Establish Lifelong Learning, Proceedings of the 2006 American Society of Engineering Education Annual Conference \& Exposition.

3) Learning Management System: Canvas, https://canvas. instructure.com/login/canvas, accessed June 30, 2015.

4) Lage, M., Platt, G., \& Treglia, M., (2000) Inverting the Classroom: A Gateway to Creating an Inclusive Learning Environment. J. of Econ. Educ. 31(1): p. 30-43.

5) Mason, G., Cook, K., Han, Y.L., and Shuman, T. R., (2015) Facilitating Problem-Based Learning with an Inverted Classroom. Proceedings of the 2015 American Society of Engineering Education Annual Conference \& Exposition.

6) Mason, G., Shuman, T., Cook, K., (2013) Comparing the Effectiveness of an Inverted Classroom to a Traditional Classroom in an Upper Division Engineering Course, IEEE Transactions on Education, 56(4): p. 430-435.

7) Matthew, R. G. S., \& Hughes, D. C. (1994) Getting at deep learning: A problem-based approach. Engineering Science and Education Journal 3(5): p. 234-240.

8) National Science Foundation, Directorate for Education and Human Resources, TUES, Award Number 1245455.

9) Norman, G. and Schmidt, H., (2000) Effectiveness of Problem-Based Learning Curricula: Theory, Practice, and Paper Darts. Medical Education 34: p. 721-728.

10) Prince, M. \& Felder, R., (2006) Inductive Teaching and Learning Methods: Definitions, Comparisons, and Research Bases. J. of Eng. Educ., 95(2): p. 123-138.

11) Prince, M., (2004) Does Active Leaming Work? AReview of the Research. J. of Eng. Educ. 93(3): p. 223-231.

12) Prince, M., Vigeant, M., and Nottis, K. (2012) Development of the Heat and Energy Concept Inventory: Preliminary Results on the Prevalence and Persistence of Engineering Students' Misconceptions, J. of Eng. Educ., 101(3): Pages: 412-438

13) Rais-Rohani, M., Walters, A., \& Vizzini, A., (2010) Emporium Based Redesign of Statics: An Innovative Approach to Enhance Learning and Reduce Costs. Proceedings of the 2010 American Society of Engineering Education Annual Conference \& Exposition.

14) Roselli, R. J. and Brophy, S. P., (2007) Effectiveness of challenge-based instruction in biomechanics, J. of Eng. Educ. 95(4): p. 311-324.

15) Terenzini, P. T., Cabrera, A. F., Colbeck, C. L., Parente, J. M., \& Bjorklund, S. A., (2001) Collaborative learning vs. lecture/discussion: Students' reported learning gains. J. of Eng. Educ, 90(1): p. 123-130.

16) Yadav, A., Subedi, D., Lundeberg, M.A., \& Bunting, C.F., (2011) Problem-based Learning in Electrical Engineering, J. of Eng. Educ., 100(2): p. 253-280.

17) Zappe, S., Leicht, R., Messner, J., Litzinger, T., and Woo Lee, H. (2009) "Flipping" the Classroom to Explore Active Learning in a Large Undergraduate Course. Proceedings of the 2009 American Society of Engineering Education Annual Conference \& Exposition.

18) Zull, J., (2002) The Art of Changing the Brain: Enriching the Practice of Teaching by Exploring the Biology of Learning. Sterling, VA: Stylus Publishing. p. 148.

Paper sent to revision: 12.03.2015.

Paper ready for publication: 03.06.2016. 